\title{
ASO Visual Abstract: Stepwise Limited Axillary Lymph Node Dissection Based on Lymphatic Drainage from the Breast to Decrease Breast Cancer-Related Lymphedema: A Randomized Controlled Trial
}

Qianqian Yuan, $\mathrm{MD}^{1}$, Jinxuan Hou, MD, $\mathrm{PhD}^{1}$, Rui Zhou, MD, $\mathrm{PhD}^{1}$, Lewei Zheng, $\mathrm{MD}^{1}$, Fang Lu, MD', Tong Deng, $\mathrm{MD}^{2}$, Wenbo Zhou, MD, $\mathrm{PhD}^{3}$, and Gaosong $\mathrm{Wu}, \mathrm{MD}$, $\mathrm{PhD}^{1}$

${ }^{1}$ Department of Thyroid and Breast Surgery, Zhongnan Hospital of Wuhan University, Wuhan, Hubei, People's Republic of China; ${ }^{2}$ Center for Evidence-Based and Translational Medicine, Zhongnan Hospital of Wuhan University, Wuhan, People's Republic of China; ${ }^{3}$ Department of Surgery, Dongfeng General Hospital affiliated with Hubei Medical College, Shiyan, Hubei, People's Republic of China

As described in our study (https://doi.org/10.1245/s104 34-021-10526-9), extensive axillary dissection is related to a high occurrence rate of morbidity. The randomized controlled trial confirmed that the axillary surgery based on lymph drainage from breast could limit surgical extent for node-positive breast cancer patients.

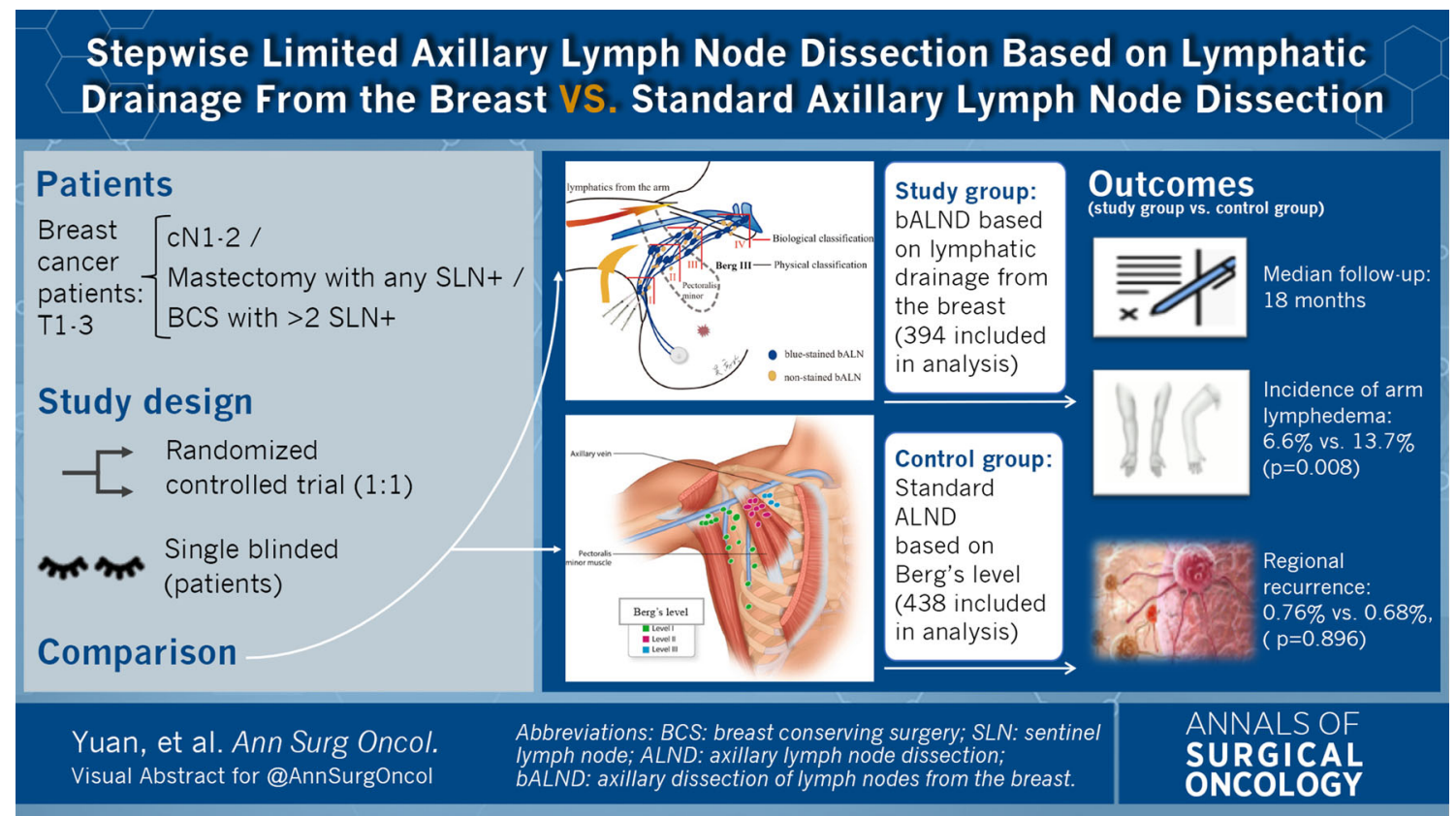

(C) Society of Surgical Oncology 2021

Published Online: 24 August 2021

G. $\mathrm{Wu}, \mathrm{MD}, \mathrm{PhD}$

e-mail: wugaosong@whu.edu.cn

Publisher's Note Springer Nature remains neutral with regard to jurisdictional claims in published maps and institutional affiliations. 